\title{
Combining biofeedback with stress management interventions: a systematic review of physiological and psychological effects
}

Nele A.J. De Witte ${ }^{a}$, Inez Buyck ${ }^{a, b}$, \& Tom Van Daele ${ }^{a}$

a Expertise Unit Psychology, Technology \& Society, Thomas More University of Applied Sciences, Antwerp, Belgium

b LUCAS, Centre for Care Research and Consultancy, KU Leuven

Running title: Combining biofeedback with stress management

Corresponding author

Nele AJ De Witte

Thomas More University of Applied Sciences

Molenstraat 8

2018 Antwerpen

E-mail: nele.dw@thomasmore.be

Tel. + $32(0) 34321891$

ORCID ID

Nele De Witte: 0000-0001-6313-7256

Inez Buyck: 0000-0002-3711-5165

Tom Van Daele: 0000-0001-9237-9297

\section{Acknowledgements}

This work was written within the Carewear project, funded by a VLAIO TETRA grant (grants IWT.150614 and HBC.2016.0099). 


\begin{abstract}
Current mental healthcare systems experience difficulties meeting the challenges of a growing population with elevated stress symptoms. Outpatient stress management interventions have already proven to be effective in routine care and recent technological advances now allow to expand such interventions, for example by adding a physiological component like biofeedback. Adding biofeedback to stress management interventions appears promising, but there is a lack of insight into the general conceptualization and evaluation of the resulting interventions, both in relation to psychological and physiological stress indicators. A comprehensive literature search was performed to investigate stress management interventions with a biofeedback component. This systematic review provides an overview of these interventions and explores to what extent they can improve both physiological and psychological indicators of stress. Fourteen RCTs were included. A large diversity was observed in intervention design and effectiveness. Nevertheless, there is preliminary evidence that the use of biofeedback can improve both physiological and psychological indicators of stress. Biofeedback could provide an accessible and low-cost addition to stress interventions. Further research into the effectiveness of different components of biofeedback interventions is needed.
\end{abstract}

Keywords: Biofeedback, stress reduction, mHealth, effectiveness, heart rate variability 


\section{Introduction}

Stress-related problems are becoming increasingly common and are associated with large health risks (Van Daele, Hermans, Van Audenhove, \& Van den Bergh, 2012). There is a need for interventions that can capture and improve the complex interplay between physiological and psychological stress processes in daily life. Technological advances allow existing psychophysiological laboratory designs for stress management to be modified for use outside of the lab, where mHealth applications could provide immediate feedback in a way that has not yet been possible in traditional mental healthcare (Williams, 2016). mHealth refers to the use of mobile information and communication technology, such as mobile computers, medical sensors, and wearable devices in healthcare (Istepanian, Jovanov, \& Zhang, 2004). However, prior to making the translation from experimental to clinical applications, research into the underlying mechanisms providing effectiveness, both on a psychological and a physiological level, is needed to establish which interventions have the largest potential for broad application.

Stress is a complex phenomenon that is triggered by a psychological or physical threat to homeostasis and consists of a variety of psychological, behavioral, and physiological responses (Bali \& Jaggi, 2015). There are many different potential sources of stress, such as work-related stress, stress due to family conditions or stress associated with medical or physical illness (such as chronic pain). Experiencing mild stress is not maladaptive or unhealthy in itself, but experiencing high levels of stress without sufficient recovery is a substantial health risk. Elevated and prolonged experience of stress is a common problem, which has a negative impact on both mental and physical health, and is associated with large economic costs (American Psychiatric Association, 2016; Cooper \& Dewe, 2008). Current mental healthcare 
systems have difficulties meeting the challenges of a growing population of individuals with elevated stress. A recent survey showed that $75 \%$ of Americans had experienced at least one symptom of stress (e.g., feeling nervous, being irritable or experiencing fatigue) in the past month (American Psychological Association, 2017). This is a 4\% increase as compared to the previous measurement in 2016.

Stressful situations can evoke changes in heart rate, heart rate variability (HRV), blood pressure, electrodermal activity (EDA), and breathing rate (Chrousos \& Gold, 1992; Jarczok et al., 2013; Lin, Lin, Lin, \& Huang, 2011). Such physiological parameters can be a useful addition to self-report data, since these do not suffer from reporting or social desirability biases. An example of an intervention strategy strongly based on physiological processes is biofeedback. Biofeedback works to help clients improve their performance and health by gaining voluntary control over real-time physiological processes, such as HRV or EDA (Dillon, Kelly, Robertson, \& Robertson, 2016). Formerly, a large disadvantage of interventions based on physiology was the need for large and expensive devices, which reduced mobility and therefore generalizability outside of the lab. However, the advance of mHealth can reduce the cost and increase the impact of psychophysiological interventions. Wearables have the potential to non-invasively collect behavioral and physiological data and thereby provide additional information that can guide treatment.

The review of Schoenberg and David (2014) shows that biofeedback can be a successful intervention to treat psychiatric symptoms. Biofeedback appears especially relevant when maladaptive physiological mechanisms (such as heightened autonomic nervous system activity) are at play, which is the case in stress experiences. The mechanisms of change in psychophysiological interventions are still largely unknown. Wheat and Larkin (2010) show that HRV biofeedback can induce significant changes 
in physiological parameters in different medical and psychiatric disorders. However, very little research directly assesses the relationship between physiological and psychological outcomes of biofeedback. It remains unclear whether physiological changes are a prerequisite to psychological effects of such psychophysiological interventions.

As highlighted in the previous paragraphs, psychophysiological parameters could be relevant indicators for mental health, with the required technology to measure these parameters becoming increasingly low-cost and less invasive. As such technology now allows to (pro)actively monitor or intervene outside of highly controlled lab settings, the question arises to what extent there is already evidence available on the use and added value of psychophysiological interventions in mental healthcare. The current systematic review focuses on the question whether there is any evidence for using biofeedback in the context of stress management interventions. Additionally, the association between physiological and psychological outcomes of these interventions is explored.

\section{Method}

A search of the literature was performed using broad keywords such as "physiolog*" and "psychophysiolog*" combined with "intervention" and "stress". This resulted in a striking amount of articles, but it became evident that controlled research into psychophysiological interventions for stress was mostly confined to biofeedback. A closer inspection of these manuscripts also revealed that a substantial subgroup of results focused on stress in the context of posttraumatic stress disorder (PTSD) or urinary stress incontinence. The current review is focused on the management of ongoing psychological stressors (e.g., demanding occupations or chronic pain) and, therefore, PTSD and urinary stress incontinence are out of scope. Consequently, the 
focus of the literature search was narrowed by use of the PICO-TS model to improve the relevance of the results and maximize comparability between studies. The current review aims to investigate the general population $(P)$ with potential stress complaints. The intervention (I) is the main focus of the review and consists of biofeedback, either stand-alone or in addition to other stress management interventions. There was a special interest in mobile health interventions (using wearable devices) when they were available. There were no requirements pertaining to the control condition $(C)$, but the reported outcomes $(\mathrm{O})$ did need to consist of both physiological and psychological indices. No timings ( $T$ ) were specified and with regard to study design (S), only randomized controlled trials were included.

A literature search of studies published until September 2017 was set up through search engines PubMed (MEDLINE), Web of Science, PsycINFO, and Cochrane Library database. The systematic search implemented the following string of keywords: (biofeedback OR wearable) AND stress NOT ("urinary" or posttraumatic or PTSD) AND (interven* OR treat* OR ther* OR manag*). Articles were selected for review based on three inclusion criteria: (1) studies implemented psychophysiological indices in a stress management intervention; (2) study designs were randomized controlled trials with a valid psychological as well as physiological measure of stress before and after the intervention; (3) articles needed to be published in an international, peer-reviewed journal and written in English. Studies were excluded when psychophysiological indices were used for diagnostic purposes only.

In a first step, two authors (IB and TVD) independently evaluated titles and abstracts for eligibility criteria. After resolving disagreements through discussion, the same authors were involved in full text evaluation. Subsequently, reference sections of the included studies were manually inspected for additional articles, yet no 
supplemental studies could be included. The studies that were found showed large diversity in the design and outcome variables, thereby eliminating the possibility of performing a meta-analysis. Relevant data on the samples, interventions and outcomes variables was extracted from the articles and summarized in tables. Additionally, a Fisher's Exact test was performed to investigate the association between the occurrence of physiological and psychological outcomes.

A risk of bias analysis was conducted using the Cochrane Risk of Bias Tool (Higgins et al., 2011). The included studies were screened for selection bias, performance bias, detection bias, attrition bias and reporting bias. Studies were considered to be highly susceptible for selection bias if violations were detected in the random assignment of participants to intervention or control groups. Selection bias was regarded low if adequate procedures regarding random group assignment were conducted, resulting in comparable groups to be investigated. Performance bias was considered to be high when there was no blinding (or masking) of study participants and personnel. Although difficult to set up in biofeedback studies, such a procedure reduces the risk that mere knowledge of the offered intervention affects outcome. When successful blinding was undertaken, this bias was considered low. Detection bias was considered to be high when researchers analyzing the data were aware of the intervention allocated to participants. Contrary, if the blinding of these outcome assessors was assured, risk of bias was considered to be low. A high risk for attrition bias was considered to be present in case of incomplete outcome data from the analyses, usually due to drop-out of participants. Studies were regarded to be low in risk for attrition bias if the data of each outcome measure were complete. Selective outcome reporting, i.e., not reporting the results of one of the outcome measures, was considered an indication of reporting bias. Studies were evaluated low in reporting bias 
if the results of all outcome measures were reported, in comparison to published study protocols. In all risk of bias analyses, insufficient details on the respective aspect of the study methodology resulted in a statement of unclear risk of bias.

\section{Results}

\section{Study selection}

The search generated 2056 potentially relevant articles (Figure 1), which were reduced to 1718 articles after removal of duplications. A total of 1605 articles were eliminated following title and abstract screening. Finally, after reading the full text another 85 articles were excluded because they did not fulfil inclusion criteria. In all, this resulted in the inclusion of 14 articles for review.

- enter Figure 1 about here -

\section{Risk of bias evaluation}

All studies randomized participants across study conditions, resulting in satisfactory conditions in terms of selection bias (Table 1). Performance bias was often considered to be present, as clear-cut control conditions were frequently used, with only a single study opting for a double blind design. Furthermore, it was difficult to assess whether any detection bias occurred, as most studies failed to provide input on whether or not outcome assessors were blinded. Attrition bias did seem to be present in several studies. This is typically due to drop-out of participants during the intervention or assessment, resulting in incomplete compilation of data. Drop-out rate itself was, however, well documented in most studies. Finally, no study protocols appeared to have been pre-published, which is however, only a fairly recent practice. Most articles did make use of a non-published protocol, or provided a comprehensive overview of their study results. It was therefore concluded that overall there seemed to be little evidence of reporting bias. 
- enter Table 1 about here -

\section{Study focus and sample}

As Table 2 illustrates, the majority of included studies focused specifically on stress management or stress reduction, although one study was aimed at general selfcontrol (Mackay et al., 2015). The stress interventions were implemented in a healthy population (Dillon et al., 2016; Kotozaki et al., 2014; Murphy, 1984; Whited, Larkin, \& Whited, 2014), a population with demanding job characteristics (Allen \& Blanchard, 1980; Lemaire, Wallace, Lewin, de Grood, \& Schaefer, 2011; McCraty, Atkinson, Lipsenthal, \& Arguelles, 2009; Sutarto, Wahab, \& Zin, 2012), or in a medical context, targeting patients with chronic pain (Berry et al., 2014; Hallman, Olsson, von Schéele, Melin, \& Lyskov, 2011), multiple sclerosis (Mackay et al., 2015), heart disease (Nolan et al., 2005), obesity (Teufel et al., 2013), and pregnant women at risk for preterm labor (Siepmann et al., 2014). In total, the included studies comprised 488 participants, of which $51 \%$ was female $(n=250)$. Participants were between 18 and 60 years old (pooled $M=39.72$, pooled $S D=7.61$; Allen and Blanchard (1980) were not included in the pooled statistics since they only reported age range).

- enter Table 2 about here -

\section{Biofeedback intervention}

Nine studies implemented stress interventions that relied on variations of biofeedback on heart rate (Kotozaki et al., 2014) and heart rate coherence or HRV (Berry et al., 2014; Hallman et al., 2011; Lemaire et al., 2011; McCraty et al., 2009; Nolan et al., 2005; Siepmann et al., 2014; Sutarto et al., 2012; Whited et al., 2014; Table 3). Two recent studies used EDA as the leading physiological parameter for biofeedback (Dillon et al., 2016; Teufel et al., 2013), while in two older studies, 
feedback was provided on electromyographic (EMG) activity (Allen \& Blanchard, 1980; Murphy, 1984). One final study applied breathing rate and muscle tension biofeedback (Mackay et al., 2015).

The duration of the biofeedback interventions ranged from one single session (Dillon et al., 2016) to an intervention that was spread out over the course of 12 weeks (McCraty et al., 2009), with most interventions being implemented for approximately four weeks (Berry et al., 2014; Kotozaki et al., 2014; Lemaire et al., 2011; Murphy, 1984; Nolan et al., 2005). The length and number of sessions showed large variability as well. Most studies encouraged daily practice of the learned skills (Allen \& Blanchard, 1980; Hallman et al., 2011; Kotozaki et al., 2014; Lemaire et al., 2011; Mackay et al., 2015; McCraty et al., 2009; Murphy, 1984; Sutarto et al., 2012; Teufel et al., 2013; Whited et al., 2014).

The studies offered biofeedback as a stand-alone intervention (Dillon et al., 2016; Hallman et al., 2011; Kotozaki et al., 2014; Murphy, 1984; Siepmann et al., 2014; Sutarto et al., 2012; Teufel et al., 2013) or as part of a broader intervention program for stress management (Allen \& Blanchard, 1980; Berry et al., 2014; Lemaire et al., 2011; Mackay et al., 2015; McCraty et al., 2009; Nolan et al., 2005; Whited et al., 2014). The training was offered in a controlled laboratory setting (Berry et al., 2014; Dillon et al., 2016; Hallman et al., 2011; Mackay et al., 2015; Nolan et al., 2005; Teufel et al., 2013; Whited et al., 2014), at work (Allen \& Blanchard, 1980; Murphy, 1984; Sutarto et al., 2012), at home (Kotozaki et al., 2014), or outside of the lab without further specifications (Lemaire et al., 2011; McCraty et al., 2009). Siepmann et al. (2014) did not specify the location of the intervention.

- enter Table 3 about here - 


\section{Control condition}

The implemented control conditions were also characterized by high levels of diversity. Six studies included passive control groups, specifically a waiting list control group (Allen \& Blanchard, 1980; McCraty et al., 2009; Murphy, 1984; Teufel et al., 2013) or no intervention (Kotozaki et al., 2014; Whited et al., 2014). However, Allen and Blanchard (1980) and Murphy (1984) additionally included a second active control condition. Active control conditions consisted of standard care for stress management (Berry et al., 2014; Nolan et al., 2005), individual and group discussions on stress (Allen \& Blanchard, 1980), a breathing protocol (Hallman et al., 2011), educational information (Lemaire et al., 2011), muscle relaxation (Murphy, 1984), or a combination of relaxation, mindfulness, social support and education (Mackay et al., 2015). Finally, three studies designed a control condition with corresponding features to the biofeedback intervention, such as playing a game (Dillon et al., 2016), presenting the visuals of the experimental intervention at the same frequency and duration, but without instruction (Siepmann et al., 2014), or physiological monitoring without providing biofeedback (Sutarto et al., 2012).

\section{Outcome measures}

Most studies evaluated physiological treatment effects through the measure that was implemented in the biofeedback condition, specifically frontal EMG (Allen \& Blanchard, 1980; Murphy, 1984), EDA (Teufel et al., 2013), muscle tension and breathing rate (Mackay et al., 2015), and HRV (coherence) in a resting state, in response to stress, or in a relaxation condition (Berry et al., 2014; Hallman et al., 2011; Nolan et al., 2005; Siepmann et al., 2014; Sutarto et al., 2012; Whited et al., 2014). However, four studies also used different physiological modalities in the outcome measures as compared to the biofeedback intervention, such as Dillon et al. (2016) 
who assessed the effect of EDA biofeedback on heart rate, Kotozaki et al. (2014) who used salivary cortisol and grey matter volumes as outcome measures for heart rate and cerebral blood flow biofeedback, and Lemaire et al. (2011) and McCraty et al. (2009) who implemented HRV coherence biofeedback and measured heart rate, blood pressure and several molecules (such as cortisol). The included studies measured HRV in both the frequency and time domain, with most studies implementing multiple HRV indices. With regard to the measurement of psychological treatment effects, there is not a golden standard for the measurement of stress. The Perceived Stress Scale (PSS; Cohen, Kamarck, \& Mermelstein, 1983) was used three times (Berry et al., 2014; Nolan et al., 2005; Whited et al., 2014) and the Depression Anxiety Stress Scales (DASS; Lovibond \& Lovibond, 1995) was included twice (Mackay et al., 2015; Sutarto et al., 2012), all of the other studies implemented different assessments.

\section{Effects of the intervention}

Berry et al. (2014), Dillon et al. (2016), and Kotozaki et al. (2014) observed beneficial effects of biofeedback for stress management as compared to the control condition in both the physiological and psychological domain. Five additional studies observed a significant physiological effect of the intervention, as compared to the control condition (Hallman et al., 2011; Murphy, 1984; Nolan et al., 2005; Sutarto et al., 2012; Whited et al., 2014). Finally, one study observed improved psychological outcomes in the biofeedback intervention, as compared the control condition (Lemaire et al., 2011). HRV was the most commonly affected physiological outcome variable, specifically HRV in recovery from stress (Hallman et al., 2011; Nolan et al., 2005; Sutarto et al., 2012; Whited et al., 2014) or at rest (Hallman et al., 2011).

A follow-up measurement was included in five studies. Teufel et al. (2013) observed that both psychological and physiological effects remained or even improved 
until 3 months follow-up. Lemaire et al. (2011) observed maintained psychological effects at 28 days follow-up and Murphy (1984) detected maintained physiological effects at three months follow-up. Siepmann et al. (2014) did not measure stress immediately after the intervention but did find a reduction in stress at four weeks followup. Finally, Allen and Blanchard (1980) did not find an effect of biofeedback on selfreported stress immediately after the intervention or at six weeks follow-up (these authors did not include a physiological follow-up measurement).

\section{Association between physiological and psychological effects}

Table 4 provides an overview of the occurrence of significant psychological and physiological outcomes, as compared to the control condition, in the fourteen included studies. The results showed that $38 \%$ of studies observing beneficial physiological outcomes also observed reduced stress levels and $75 \%$ of studies with reduced stress levels also observed improved physiological outcomes, a difference that was not significant ( $p=.580$, two tailed Fisher's Exact test).

- enter Table 4 about here -

\section{Effectiveness related to different components of the biofeedback intervention and sample}

The included studies showed large diversity in the characteristics of the implemented biofeedback intervention. Different physiological systems were targeted, interventions were offered for varying durations of time, were applied both in a lab and real-life context, used different control conditions, and were operationalized as a standalone intervention or embedded in a broader intervention program. However, when plotting the occurrence of certain characteristics (such as duration) of a study against positive outcomes, visual inspection of the data did not reveal clear indications for 
better performance based on differences in this characteristic. Outcomes did not appear to improve when additional interventions were included, a real-life context was used or the duration was longer than four weeks.

Additionally, there were differences in the characteristics of the samples. The current review included both healthy subjects and individuals with health problems. There was no clear tendency for improved effectiveness of biofeedback in either group. It is difficult to compare the levels of stress between individuals and participant groups, since stress is a highly subjective experience and different assessment tools were used to measure stress. Dillon et al. (2016) induced stress in healthy participants prior to biofeedback and McCraty et al. (2009) reported that $21 \%$ of the sample showed high cortisol levels at baseline. However, the other studies did not induce stress or report whether their samples displayed elevated stress at baseline. Individuals with severe stress-related problems might show more room for improvement on the outcome variables (e.g., HRV) as compared to participants with less severe problems. However, the current data do not allow assessing whether stress levels at baseline influenced the outcome of biofeedback.

\section{Discussion}

Elevated stress is a common negative psychological state that is associated with physiological changes. Therefore, stress management programs might benefit from the addition of a psychophysiological component. The purpose of this review was to investigate whether stress management interventions with a biofeedback component could improve both physiological and psychological indicators of stress. The results show that there is large diversity in the characteristics and effectiveness of the included interventions. No association between the occurrence of physiological and 
psychological effects could be observed. There is a need for further research assessing which components of biofeedback can improve stress outcomes.

Three studies observed significant improvements in both physiological and psychological stress indices in the biofeedback condition as compared to the control condition. Berry et al. (2014) implemented HRV coherence biofeedback in the context of chronic pain and achieved significantly higher HRV coherence and lower PSS scores after the intervention as compared to treatment as usual. The stress management study of Kotozaki et al. (2014) found that heart rate and cerebral blood flow biofeedback led to significantly decreased cortisol levels, decreased subjective stress, and neural changes. The mHealth design of Dillon et al. (2016) showed that EDA biofeedback games significantly decreased heart rate and perceived stress in comparison to a non-biofeedback game in a healthy population.

In addition to these three studies that observed effects on both outcome variables, six studies observed significantly stronger improvement in either physiological or psychological variables. HRV biofeedback significantly improves HRV in different participant populations, specifically individuals with stress-related chronic neck pain (Hallman et al., 2011), patients with coronary heart disease (Nolan et al., 2005), labourers (Sutarto et al., 2012), and students (Whited et al., 2014). Murphy et al. (1984) showed that EMG biofeedback leads to significantly lower EMG values in a working class population. Nolan et al. (2005) and Sutarto et al. (2012) additionally observed reduced PSS and DASS scores after the intervention, but there was no significant difference with the control group. Lemaire et al. (2011) implemented stress management with HRV coherence biofeedback and documented lower perceived stress levels that remained at 28 days follow-up. 
The remaining five studies also observed improvement in some of the outcome variables, but group differences did not reach significance. Stress was targeted in white-collar workers by Allen \& Blanchard (1980) and McCraty et al. (2009) through EMG and HRV coherence biofeedback. These studies recorded EMG and HRV reductions that did not differ from the control condition. No psychological effects were found. Mackay et al. (2015) and Siepmann et al. (2014) on the other hand observed non-significant psychological effects, but no effects on breathing rate, muscle tension and heart rhythm, after implementing breathing rate and muscle tension biofeedback in multiple sclerosis patients or HRV biofeedback in pregnant women, respectively. Finally, in the study of Teufel et al. (2013) EDA biofeedback was associated with small to medium effects on EDA and small to large effects on perceived stress in an obese population, but no group differences could be found.

Several aspects of the study design could contribute to differences in the effectiveness of biofeedback. However, outcomes did not appear to vary according to specific intervention characteristics, such as duration, context or additional interventions. Sample characteristics could hamper statistical power to detect group differences. The studies included in the current review suffered from small sample sizes, sometimes reaching no more than ten participants per condition (Allen \& Blanchard, 1980; Berry et al., 2014; Teufel et al., 2013). Additionally, the majority of studies did not report whether the included sample showed elevated stress at baseline. Healthy individuals with few stress-related symptoms may not have a lot of room for improvement in the outcome measures. Finally, individual differences and preferences can also influence effectiveness through effects on motivation, engagement, and compliance (Marcus, Stuart, Wang, Shadish, \& Steiner, 2012). 
Biofeedback is based on the concept that increased control over physiological processes can improve performance and well-being. The current review assessed changes in both the physiological and psychological domain to better understand how improvements in these domains are related to one another. While Nolan et al. (2005) did find an inverse association between subjective stress and HRV modulation (the physiological outcome measure of the study) that was limited to the biofeedback condition, the current review did not observe a significant association between physiological and psychological outcomes variables. The mechanisms of change in biofeedback remain unclear. Berry et al. (2014) propose that biofeedback combined with self-regulation techniques can increase awareness of internal psychophysiological processes and hereby improve coping techniques (for pain). Biofeedback can not only increase awareness but also promote conscious control. Dillon et al. (2016) state that stress can be caused by a perceived lack of control and that perceived control can be improved by teaching individuals how to master physiological processes through biofeedback.

The majority of included studies encouraged participants to practice the skills individually between sessions and two studies reported that over 90 percent of participants indeed performed (daily) exercises at home (Mackay et al., 2015; Whited et al., 2014). This finding is relevant for the development of mHealth applications using biofeedback since it suggests that participants are both able and motivated to apply biofeedback exercises individually and in different contexts. Benefits of an mHealth approach are that participants can use the intervention flexibly and at low cost, which can facilitate widespread adoption. A promising mHealth application for biofeedback is wearable technology, in which mobile sensory devices (e.g., wristbands) are used to non-invasively collect physiological data. Wearable devices can measure EDA 
(Villarejo, Zapirain, \& Zorrilla, 2012), breathing patterns, and heart rhythm (and accordingly allow for the calculation of HRV) (Cropley et al., 2017). There is also a growing interest in using wearables to collect blood pressure and breathing rate as a guide for stress recovery training at home (through biofeedback), but further research is needed (e.g., Uddin et al., 2016). Ideally, however, a wide range of different physiological parameters could be collected by wearables, their data integrated and subsequently used as an additional source of information to guide preventive or therapeutic interventions (De Witte, Bonroy, Debard, Sels, \& Van Daele, 2018). There are some important practical barriers for implementation of mHealth, such as commercial availability of affordable and reliable physiological measurement tools, potential problems with data security, and diverse needs (for interfaces and tools) in different populations (Munos et al., 2016).

The current review was able to include one mHealth and game-based biofeedback intervention. Dillon et al. (2016) induced stress in their participants and subsequently offered EDA biofeedback through two mobile games. This approach has several potential advantages. It maximizes opportunities for generalization since participants learn to use biofeedback when they are stressed and the medium (a smartphone) makes it flexible to use in different contexts. Additionally, gamification elements could increase engagement and motivation. However, the effect sizes of Dillon et al. (2016) were modest and no follow-up measures were included. Other mobile biofeedback applications have been developed (e.g., Gaggioli et al., 2014; Munster-Segev, Fuerst, Kaplan, \& Cahn, 2017), however, these applications still need to undergo rigorous testing and often lack gamification elements. Despite potential benefits, gamification is currently rarely included in stress management applications for adults (Hoffmann, Christmann, \& Bleser, 2017). Biofeedback video games have 
been developed for children and adolescents, such as Dojo and MindLight (Schoneveld, Lichtwarck-Aschoff, \& Granic, 2017).

Some limitations of the current review require discussion. Although the goal was to include all stress interventions using psychophysiological components, an exploratory literature search showed that this field of research was mostly limited to biofeedback interventions and the scope was consequently limited to increase comparability. A likely explanation for the lack of other interventions using psychophysiological measures is that, until recently, practical limitations (related to hardware or big data) impeded the possibilities for postponed feedback or report of psychophysiological data. As opposed to other interventions, biofeedback does not require large amounts of storage or computing power. Secondly, it is important to consider both the psychological and physiological outcome domains when investigating the effectiveness of psychophysiological interventions. Studies often did not investigate both outcome domains and could therefore not be included in the current review. The current review was only able to assess the association between these two outcome domains using dichotomous variables. Future research needs to investigate the association between physiological and psychological outcomes further by using analyses with more power, such as correlations. The included studies had very diverse samples. Comorbid conditions (such as obesity or chronic pain) could influence the effects of biofeedback. The large variability in the implemented control conditions and psychological measurement instruments did not allow to directly compare different studies and perform a meta-analysis. More high-quality standardized effectiveness studies of biofeedback interventions for stress are needed.

Taken together, the studies included in the current review suggest that biofeedback can be a promising intervention for stress management. It is feasible to 
explore the implementation of biofeedback in different contexts and in samples with stress associated to various conditions. One third of the included studies, however, did not observe any incremental effectiveness of biofeedback. Small sample sizes and large differences between study designs also impede generalization. Additional research needs to determine which components of biofeedback are effective and establish whether psychophysiological measurements are an appropriate component of stress management programs. It is feasible to offer biofeedback as a gamified mHealth application and one included study supports that this is associated with positive short-term outcomes in both physiological and self-report indicators of stress.

\section{Conflict of interest}

The authors declare that they have no conflict of interest. 


\section{References}

Allen, J. K., \& Blanchard, E. B. (1980). Biofeedback-based stress management training with a population of business managers. Biofeedback and Self-Regulation, 5(4), 427-438.

American Psychiatric Association. (2016). Stress in America: the impact of discrimination. Stress in America ${ }^{\mathrm{TM}}$ Survey.

American Psychological Association. (2017). Stress in America: The State of Our Nation. Stress in America ${ }^{\mathrm{TM}}$ Survey.

Bali, A., \& Jaggi, A. S. (2015). Clinical experimental stress studies: methods and assessment. Reviews in the Neurosciences, 26(5), 555-579. https://doi.org/10.1515/revneuro-2015-0004

Berry, M. E., Chapple, I. T., Ginsberg, J. P., Gleichauf, K. J., Meyer, J. A., \& Nagpal, M. L. (2014). Non-pharmacological Intervention for Chronic Pain in Veterans: A Pilot Study of Heart Rate Variability Biofeedback. Global Advances in Health and Medicine, 3(2), 28-33. https://doi.org/10.7453/gahmj.2013.075

Chrousos, G. P., \& Gold, P. W. (1992). The concepts of stress and stress system disorders. Overview of physical and behavioral homeostasis. JAMA, 267(9), 1244-1252.

Cohen, S., Kamarck, T., \& Mermelstein, R. (1983). A global measure of perceived stress. Journal of Health and Social Behavior, 24(4), 385-396.

Cooper, C., \& Dewe, P. (2008). Well-being - absenteeism, presenteeism, costs and challenges. Occupational Medicine, 58(8), 522-524. https://doi.org/10.1093/occmed/kqn124

Cropley, M., Plans, D., Morelli, D., Sütterlin, S., Inceoglu, I., Thomas, G., \& Chu, C. (2017). The Association between Work-Related Rumination and Heart Rate 
Variability: A Field Study. Frontiers in Human Neuroscience, 11, 27. https://doi.org/10.3389/fnhum.2017.00027

De Witte, N. A. J., Bonroy, B., Debard, G., Sels, R., \& Van Daele, T. (2018). Carewear: an internet-based platform to implement wearable technology in mental health care. Paper presented at the conferene of the European Society for Research on Internet Interventions, Dublin.

Dillon, A., Kelly, M., Robertson, I. H., \& Robertson, D. A. (2016). Smartphone Applications Utilizing Biofeedback Can Aid Stress Reduction. Frontiers in Psychology, 7, 832. https://doi.org/10.3389/fpsyg.2016.00832

Gaggioli, A., Cipresso, P., Serino, S., Campanaro, D. M., Pallavicini, F., Wiederhold, B. K., \& Riva, G. (2014). Positive technology: a free mobile platform for the selfmanagement of psychological stress. Studies in Health Technology and Informatics, 199, 25-29.

Hallman, D. M., Olsson, E. M., von Schéele, B., Melin, L., \& Lyskov, E. (2011). Effects of heart rate variability biofeedback in subjects with stress-related chronic neck pain: a pilot study. Applied Psychophysiology and Biofeedback, 36(2), 71-80. https://doi.org/10.1007/s10484-011-9147-0

Higgins, J. P., Altman, D. G., Gøtzsche, P. C., Jüni, P., Moher, D., Oxman, A. D., ... Group, C. S. M. (2011). The Cochrane Collaboration's tool for assessing risk of bias in randomised trials. BMJ, 343, d5928. https://doi.org/10.1136/bmj.d5928

Hoffmann, A., Christmann, C. A., \& Bleser, G. (2017). Gamification in Stress Management Apps: A Critical App Review. JMIR Serious Games, 5(2), e13. https://doi.org/10.2196/games.7216

Istepanian, R., Jovanov, E., \& Zhang, Y. T. (2004). Introduction to the special section on M-Health: beyond seamless mobility and global wireless health-care 
connectivity. IEEE Transactions on Information Technology in Biomedicine, 8(4), 405-414.

Jarczok, M., Jarczok, M., Mauss, D., Koenig, J., Li, J., Herr, R., \& Thayer, J. (2013). Autonomic nervous system activity and workplace stressors-A systematic review. Neuroscience and Biobehavioral Reviews, 37(8), 1810-1823. https://doi.org/10.1016/j.neubiorev.2013.07.004

Kotozaki, Y., Takeuchi, H., Sekiguchi, A., Yamamoto, Y., Shinada, T., Araki, T., ... Kawashima, R. (2014). Biofeedback-based training for stress management in daily hassles: an intervention study. Brain and Behavior, 4(4), 566-579. https://doi.org/10.1002/brb3.241

Lemaire, J. B., Wallace, J. E., Lewin, A. M., de Grood, J., \& Schaefer, J. P. (2011). The effect of a biofeedback-based stress management tool on physician stress: a randomized controlled clinical trial. Open Medicine, 5(4), e154-163.

Lin, H., Lin, H., Lin, W., \& Huang, A. (2011). Effects of Stress, Depression, and Their Interaction on Heart Rate, Skin Conductance, Finger Temperature, and Respiratory Rate: Sympathetic-Parasympathetic Hypothesis of Stress and Depression. Journal of Clinical Psychology, 67(10), 1080-1091. https://doi.org/10.1002/jclp.20833

Lovibond, S.H., \& Lovibond, P.F. (1995). Manual for the Depression Anxiety Stress Scales. (2nd. Ed.). Sydney: Psychology Foundation.

Mackay, A. M., Buckingham, R., Schwartz, R. S., Hodgkinson, S., Beran, R. G., \& Cordato, D. J. (2015). The Effect of Biofeedback as a Psychological Intervention in Multiple Sclerosis: A Randomized Controlled Study. International Journal of MS Care, 17(3), 101-108. https://doi.org/10.7224/1537-2073.2014-006 
Marcus, S. M., Stuart, E. A., Wang, P., Shadish, W. R., \& Steiner, P. M. (2012). Estimating the Causal Effect of Randomization Versus Treatment Preference in a Doubly Randomized Preference Trial. Psychological Methods, 17(2), 244254. http://doi.org/10.1037/a0028031

McCraty, R., Atkinson, M., Lipsenthal, L., \& Arguelles, L. (2009). New hope for correctional officers: an innovative program for reducing stress and health risks. Applied Psychophysiology and Biofeedback, 34(4), 251-272. https://doi.org/10.1007/s10484-009-9087-0

Munos, B., Baker, P. C., Bot, B. M., Crouthamel, M., de Vries, G., Ferguson, I., ... Wang, P. (2016). Mobile health: the power of wearables, sensors, and apps to transform clinical trials. Annals of the New York Academy of Sciences, 1375(1), 3-18. https://doi.org/10.1111/nyas.13117

Munster-Segev, M., Fuerst, O., Kaplan, S. A., \& Cahn, A. (2017). Incorporation of a Stress Reducing Mobile App in the Care of Patients With Type 2 Diabetes: A Prospective Study. JMIR Mhealth Uhealth, 5(5), e75. https://doi.org/10.2196/mhealth.7408

Murphy, L. R. (1984). Stress management in highway maintenance workers. Journal of Occupational Medicine, 26(6), 436-442.

Nolan, R. P., Kamath, M. V., Floras, J. S., Stanley, J., Pang, C., Picton, P., \& Young, Q. R. (2005). Heart rate variability biofeedback as a behavioral neurocardiac intervention to enhance vagal heart rate control. American Heart Journal, 149(6), 1137. https://doi.org/10.1016/j.ahj.2005.03.015

Schoenberg, P. L., \& David, A. S. (2014). Biofeedback for psychiatric disorders: a systematic review. Applied Psychophysiology and Biofeedback, 39(2), 109-135. https://doi.org/10.1007/s10484-014-9246-9 
Schoneveld, E. A., Lichtwarck-Aschoff, A., \& Granic, I. (2017). Preventing Childhood Anxiety Disorders: Is an Applied Game as Effective as a Cognitive Behavioral Therapy-Based Program? Prevention Science. https://doi.org/10.1007/s11121017-0843-8

Siepmann, M., Hennig, U. D., Siepmann, T., Nitzsche, K., Mück-Weymann, M., Petrowski, K., \& Weidner, K. (2014). The effects of heart rate variability biofeedback in patients with preterm labour. Applied Psychophysiology and Biofeedback, 39(1), 27-35. https://doi.org/10.1007/s10484-013-9238-1

Sutarto, A. P., Wahab, M. N., \& Zin, N. M. (2012). Resonant breathing biofeedback training for stress reduction among manufacturing operators. International Journal of Occupational Safety and Ergonomics, 18(4), 549-561. https://doi.org/10.1080/10803548.2012.11076959

Teufel, M., Stephan, K., Kowalski, A., Käsberger, S., Enck, P., Zipfel, S., \& Giel, K. E. (2013). Impact of biofeedback on self-efficacy and stress reduction in obesity: a randomized controlled pilot study. Applied Psychophysiology and Biofeedback, 38(3), 177-184. https://doi.org/10.1007/s10484-013-9223-8

Uddin, A. A., Morita, P. P., Tallevi, K., Armour, K., Li, J., Nolan, R. P., \& Cafazzo, J. A. (2016). Development of a Wearable Cardiac Monitoring System for Behavioral Neurocardiac Training: A Usability Study. JMIR Mhealth Uhealth, 4(2), e45. https://doi.org/10.2196/mhealth.5288

Van Daele, T., Hermans, D., Van Audenhove, C., \& Van den Bergh, O. (2012). Stress reduction through psychoeducation: a meta-analytic review. Health Education \& Behavior, 39(4), 474-485. https://doi.org/10.1177/1090198111419202 
Villarejo, M. V., Zapirain, B. G., \& Zorrilla, A. M. (2012). A stress sensor based on Galvanic Skin Response (GSR) controlled by ZigBee. Sensors (Basel), 12(5), 6075-6101. https://doi.org/10.3390/s120506075

Wheat, A. L., \& Larkin, K. T. (2010). Biofeedback of heart rate variability and related physiology: a critical review. Applied Psychophysiology and Biofeedback, 35(3), 229-242. https://doi.org/10.1007/s10484-010-9133-y

Whited, A., Larkin, K. T., \& Whited, M. (2014). Effectiveness of emWave biofeedback in improving heart rate variability reactivity to and recovery from stress. Applied $\begin{array}{lll}\text { Psychophysiology and } \quad \text { Biofeedback, 39(2), } & \text { 75-88. }\end{array}$ https://doi.org/10.1007/s10484-014-9243-z

Williams, A. D. (2016). Harnessing the quantified self-movement for optimal mental health and wellbeing. Paper presented at the LTA, Amsterdam. 


\section{Tables \& figures}

\section{Table 1}

Overview of risk of bias, ranging from low (-), over unclear (0) to high (+) risk of bias

\begin{tabular}{lccccc}
\hline Study & Selection bias & Performance bias & Detection bias & Attrition bias & Reporting bias \\
\hline 1. Allen \& Blanchard & - & + & - & - & - \\
2. Berry et al. (2014) & - & + & 0 & - & - \\
3. Dillon et al. (2016) & - & 0 & 0 & + & - \\
4. Hallman et al. (2011) & - & - & 0 & + & + \\
5. Kotozaki et al. (2013) & - & - & + & - & - \\
6. Lemaire et al. (2011) & - & 0 & 0 & + & - \\
7. Mackay et al. (2015) & - & + & 0 & + & + \\
8. McCraty et al. (2009) & - & + & 0 & + & - \\
9. Murphy (1982) & - & + & 0 & + & - \\
10. Nolan et al. (2005) & - & + & + & + & - \\
11. Siepmann et al. & - & + & 0 & + \\
12. Sutarto et al. (2012) & - & + & 0 & + \\
13. Teufel et al. (2013) & - & + & + & - \\
14. Whited et al. (2014) & - & + & + & + \\
\hline
\end{tabular}


Table 2

Study design features

\begin{tabular}{|c|c|c|c|c|c|c|}
\hline Study & Study focus & $\begin{array}{l}\text { Sample } \\
\text { size (\# } \\
\text { female) }\end{array}$ & $\begin{array}{l}\text { Sample } \\
\text { characteristics \& } \\
\text { mean age (SD) }\end{array}$ & Physiological measurements & $\begin{array}{l}\text { Psychological } \\
\text { measurements }\end{array}$ & $\begin{array}{l}\text { Follow- } \\
\text { up }\end{array}$ \\
\hline $\begin{array}{l}\text { 1. Allen \& } \\
\text { Blanchard } \\
(1980)\end{array}$ & Stress management & $30(8)$ & $\begin{array}{l}\text { Middle-level } \\
\text { managers } \\
\text { Age range: 40-60 }\end{array}$ & $\begin{array}{l}\text { Frontal electromyography, finger } \\
\text { temperature }\end{array}$ & SSS & $\begin{array}{l}6 \text { weeks } \\
\text { (SSS) }\end{array}$ \\
\hline $\begin{array}{l}\text { 2. Berry et } \\
\text { al. (2014) }\end{array}$ & $\begin{array}{l}\text { Pain and stress } \\
\text { management }\end{array}$ & $14(1)$ & $\begin{array}{l}\text { Veterans with } \\
\text { chronic pain } \\
44.63(6.96)\end{array}$ & HRV coherence & PSS & - \\
\hline $\begin{array}{l}\text { 3. Dillon et } \\
\text { al. (2016) }\end{array}$ & Stress reduction & $50(32)$ & $\begin{array}{l}\text { Healthy adults } \\
26.7(5.1)\end{array}$ & Heart rate & $\begin{array}{l}\text { Visual Analogue } \\
\text { Scale for perceived } \\
\text { stress }\end{array}$ & - \\
\hline $\begin{array}{l}\text { 4. Hallman } \\
\text { et al. (2011) }\end{array}$ & $\begin{array}{l}\text { Autonomic regulation } \\
\text { and perceived health, } \\
\text { pain, stress and } \\
\text { disability }\end{array}$ & $24(22)$ & $\begin{array}{l}\text { Adults with stress- } \\
\text { related chronic } \\
\text { neck pain } \\
41.43(7.07)\end{array}$ & $\begin{array}{l}\text { HRV during rest, during hand } \\
\text { grip test, during cold pressor } \\
\text { test, and during deep breathing } \\
\text { test }\end{array}$ & $\begin{array}{l}\text { Stress Medicine } \\
\text { Symptom Scale }\end{array}$ & - \\
\hline $\begin{array}{l}\text { 5. Kotozaki } \\
\text { et al. }(2014)\end{array}$ & Stress management & $30(0)$ & $\begin{array}{l}\text { Healthy working } \\
\text { adults } \\
42.30(7.90)\end{array}$ & $\begin{array}{l}\text { Salivary cortisol and voxel- } \\
\text { based morphometry }\end{array}$ & $\begin{array}{l}\text { Brief Job Stress } \\
\text { Questionnaire }\end{array}$ & - \\
\hline
\end{tabular}




\begin{tabular}{|c|c|c|c|c|c|c|}
\hline $\begin{array}{l}\text { 6. Lemaire } \\
\text { et al. (2011) }\end{array}$ & Stress management & $40(17)$ & $\begin{array}{l}\text { Physicians } \\
46.3(8.35)\end{array}$ & $\begin{array}{l}\text { Heart rate, blood pressure, } \\
\text { salivary cortisol }\end{array}$ & $\begin{array}{l}\text { Scale based on PSS } \\
\text { and POQA - revised }\end{array}$ & 28 days \\
\hline $\begin{array}{l}\text { 7. Mackay } \\
\text { et al. (2015) }\end{array}$ & Self-control & $40(32)$ & $\begin{array}{l}\text { Patients with } \\
\text { multiple sclerosis } \\
45.9(12.42)\end{array}$ & Muscle tension, breathing rate & DASS & $\begin{array}{l}3 \\
\text { months } \\
\text { (DASS) }\end{array}$ \\
\hline $\begin{array}{l}\text { 8. McCraty } \\
\text { et al. (2009) }\end{array}$ & $\begin{array}{l}\text { Stress and health risk } \\
\text { reduction }\end{array}$ & $75(23)$ & $\begin{array}{l}\text { Correctional } \\
\text { officers } \\
40.00(7.88)\end{array}$ & $\begin{array}{l}\text { HRV, blood pressure, blood } \\
\text { samples, and saliva samples }\end{array}$ & POQA & - \\
\hline $\begin{array}{l}\text { 9. Murphy } \\
(1984)\end{array}$ & Stress management & $38(4)$ & $\begin{array}{l}\text { Highway } \\
\text { maintenance } \\
\text { workers } \\
42 \text { (SD not given) }\end{array}$ & Forehead electromyography & Job Stress Scale & $\begin{array}{l}3 \\
\text { months }\end{array}$ \\
\hline $\begin{array}{l}\text { 10. Nolan et } \\
\text { al. (2005) }\end{array}$ & $\begin{array}{l}\text { Stress and depression } \\
\text { reduction }\end{array}$ & $46(6)$ & $\begin{array}{l}\text { Patients with } \\
\text { coronary heart } \\
\text { disease } \\
54.52(1.26)\end{array}$ & $\begin{array}{l}\text { HRV at baseline, during } \\
\text { physical, emotional, and } \\
\text { personal stressor, and during } \\
\text { recovery }\end{array}$ & PSS & - \\
\hline $\begin{array}{l}11 . \\
\text { Siepmann et } \\
\text { al. (2014) }\end{array}$ & $\begin{array}{l}\text { Reduction of stress } \\
\text { and preterm birth }\end{array}$ & $48(48)$ & $\begin{array}{l}\text { Pregnant women } \\
\text { prone to preterm } \\
\text { labor } \\
29(5)\end{array}$ & Heart rate, HRV & $\begin{array}{l}\text { Trier Inventory for } \\
\text { the Assessment of } \\
\text { Chronic Stress }\end{array}$ & 4 weeks \\
\hline
\end{tabular}




\begin{tabular}{|c|c|c|c|c|c|c|}
\hline $\begin{array}{l}\text { 12. Sutarto } \\
\text { et al. (2012) }\end{array}$ & Stress reduction & $36(36)$ & $\begin{array}{l}\text { Manufacturing } \\
\text { operators } \\
36.30(10.14)\end{array}$ & $\begin{array}{l}\text { HRV during rest, stressor, and } \\
\text { recovery }\end{array}$ & DASS & - \\
\hline $\begin{array}{l}\text { 13. Teufel et } \\
\text { al. (2013) }\end{array}$ & $\begin{array}{l}\text { Self-efficacy and stress } \\
\text { reduction }\end{array}$ & $30(30)$ & $\begin{array}{l}\text { Obese adults } \\
48.67(9.94)\end{array}$ & $\begin{array}{l}\text { Electrodermal activity to food } \\
\text { stimuli }\end{array}$ & $\begin{array}{l}\text { Perceived Stress } \\
\text { Questionnaire }\end{array}$ & $\begin{array}{l}3 \\
\text { months }\end{array}$ \\
\hline $\begin{array}{l}\text { 14. Whited } \\
\text { et al. (2014) }\end{array}$ & Stress reduction & $27(23)$ & $\begin{array}{l}\text { Students } \\
22.54(3.82)\end{array}$ & $\begin{array}{l}\text { HRV at rest, during stressor and } \\
\text { during recovery }\end{array}$ & PSS & - \\
\hline
\end{tabular}

Note. Pooled means were calculated for age (in years) when no total group means were provided. Allen \& Blanchard (1980) and Murphy (1982)

did not report the mean and/or standard deviation of age. DASS = Depression Anxiety Stress Scales, HRV = heart rate variability, POQA =

Personal and Organizational Quality Assessment, PSS = Perceived Stress Scale, SSS = Subjective Stress Scale 
Table 3

Overview of the intervention characteristics and results of the included studies

\begin{tabular}{|c|c|c|c|c|c|c|}
\hline Study & $\begin{array}{l}\text { Intervention } \\
\text { duration }\end{array}$ & $\begin{array}{l}\text { Experimental } \\
\text { intervention }\end{array}$ & $\begin{array}{l}\text { Control } \\
\text { condition(s) }\end{array}$ & Physiological effects & $\begin{array}{l}\text { Psychological } \\
\text { effects }\end{array}$ & Conclusion \\
\hline $\begin{array}{l}\text { 1. Allen \& } \\
\text { Blanchard } \\
(1980)\end{array}$ & $\begin{array}{l}6 \text { weeks } \\
55 \text { min / } \\
\text { week } \\
+ \text { daily } \\
\text { practice }\end{array}$ & $\begin{array}{l}\text { EMG BF, } \\
\text { progressive } \\
\text { relaxation, } \\
\text { abdominal } \\
\text { breathing, and } \\
\text { stress inoculation } \\
\text { training }\end{array}$ & $\begin{array}{l}\text { (1) WLC } \\
\text { (2) } 6 \text { weekly } \\
\text { individual and } \\
\text { group sessions } \\
\text { on stress }\end{array}$ & $\begin{array}{l}\text { Decrease in basal frontal } \\
\text { EMG and frontal EMG } \\
\text { during stress recovery: INT } \\
\text { \& C }\end{array}$ & No effects & $\begin{array}{l}\text { Physiological effects } \\
\text { but no superior } \\
\text { effect of INT }\end{array}$ \\
\hline $\begin{array}{l}\text { 2. Berry } \\
\text { et al. } \\
(2014)\end{array}$ & $\begin{array}{l}4 \text { weeks } \\
1 \text { session / } \\
\text { week }\end{array}$ & $\begin{array}{l}\text { HRV coherence } \\
\text { BF and TAU }\end{array}$ & TAU & $\begin{array}{l}\text { POST HRV coherence: INT } \\
>\mathrm{C}\end{array}$ & $\begin{array}{l}\text { POST perceived } \\
\text { stress: INT < C }\end{array}$ & $\begin{array}{l}\text { Larger physiological } \\
\text { and psychological } \\
\text { effects in INT than C }\end{array}$ \\
\hline $\begin{array}{l}\text { 3. Dillon } \\
\text { et al. } \\
(2016)\end{array}$ & $\begin{array}{l}1 \text { session of } \\
30 \mathrm{~min}\end{array}$ & $\begin{array}{l}\text { Two EDA BF } \\
\text { games }\end{array}$ & $\begin{array}{l}\text { Non- } \\
\text { biofeedback } \\
\text { game }\end{array}$ & POST HR: INT < C & $\begin{array}{l}\text { POST perceived } \\
\text { stress: INT < C }\end{array}$ & $\begin{array}{l}\text { Larger physiological } \\
\text { and psychological } \\
\text { effects in INT than C }\end{array}$ \\
\hline $\begin{array}{l}4 . \\
\text { Hallman } \\
\text { et al. } \\
(2011)\end{array}$ & $\begin{array}{l}10 \text { weeks } \\
1 \text { session / } \\
\text { week }\end{array}$ & $\begin{array}{l}\text { Resonance HRV } \\
\text { BF }\end{array}$ & $\begin{array}{l}\text { Breathing } \\
\text { protocol in } \\
\text { week } 1 \text { and } 10 \text {, }\end{array}$ & $\begin{array}{l}\text { POST HRV during rest, } \\
\text { reactivity to stress and } \\
\text { recovery from stress: INT > } \\
\text { C }\end{array}$ & No effects & $\begin{array}{l}\text { Larger physiological } \\
\text { effects in INT than C } \\
\text { (but not in all HRV } \\
\text { indices) }\end{array}$ \\
\hline
\end{tabular}


$+15 \min$

daily

practice

5.

Kotozaki

4 weeks

$5 \mathrm{~min} /$ day

et al.

(2014)

Lemaire

4 weeks

et al.

3 sessions

of $5 \mathrm{~min} /$

(2011)

day
$\mathrm{HR}$ and $\mathrm{CBF} B F$

No intervention

cortisol level: INT > C

Increase in grey matter

volume of right lateral

orbitofrontal cortex and

left subgenual anterior

cingulate cortex: INT > C

No effects

brochure \&

BF, rhythmic

7. Mackay 3 weeks

et al.

(2015) breathing, self-

generated positive

emotion, and

components

control condition

biweekly

contact with

research

assistant

(+ BF training

after 4 weeks)

\section{Breathing rate and Relaxation, No effects}

muscle tension BF mindfulness,

and components social support,

control condition \& education
$60 \mathrm{~min} /$

week

+ daily

practice

\section{Decrease in Larger physiological \\ tension and \\ stressors of and psychological \\ effects in INT than C}

working

environment score:

INT $>$ C

\section{Decrease in}

Larger psychological

perceived stress:

INT > C

Effects INT

maintained at FU

Decrease in stress: Psychological

INT effects but no significant group differences 


\begin{tabular}{|c|c|c|c|c|c|c|}
\hline $\begin{array}{l}8 . \\
\text { McCraty } \\
\text { et al. } \\
(2009)\end{array}$ & $\begin{array}{l}\text { 2-day } \\
\text { training } \\
\text { program } \\
+3 \text { months } \\
\text { of daily } \\
\text { practice }\end{array}$ & $\begin{array}{l}\text { HRV coherence } \\
\text { BF and "Power to } \\
\text { Change } \\
\text { Performance" } \\
\text { program }\end{array}$ & WLC & $\begin{array}{l}\text { Decrease in blood pressure, } \\
\text { HR, and dehydroepiandro- } \\
\text { sterone (DHEA) and } \\
\text { increase in HRV: INT } \\
\text { Decrease in cholesterol and } \\
\text { glucose: INT \& C }\end{array}$ & No effects & $\begin{array}{l}\text { Physiological effects } \\
\text { in INT but no } \\
\text { significant group } \\
\text { differences }\end{array}$ \\
\hline $\begin{array}{l}\text { 9. Murphy } \\
\text { (1984) }\end{array}$ & $\begin{array}{l}2 \text { weeks } \\
60 \text { min / day } \\
+ \text { practice } \\
\text { between } \\
\text { sessions }\end{array}$ & Forehead EMG BF & $\begin{array}{l}\text { (1) WLC } \\
\text { (2) MR }\end{array}$ & $\begin{array}{l}\text { Decrease in EMG: INT > } \\
\text { WLC } \\
\text { Percentages of EMG } \\
\text { reduction at FU: INT > MR > } \\
\text { WLC }\end{array}$ & No effects & $\begin{array}{l}\text { Larger physiological } \\
\text { effects in INT than C }\end{array}$ \\
\hline $\begin{array}{l}\text { 10. Nolan } \\
\text { et al. } \\
(2005)\end{array}$ & $\begin{array}{l}4 \text { weeks } \\
5 \text { sessions } \\
\text { of } 90 \mathrm{~min}\end{array}$ & $\begin{array}{l}\text { Paced breathing } \\
\text { guided by HRV BF } \\
\text { and cognitive- } \\
\text { behavioral training }\end{array}$ & TAU & $\begin{array}{l}\text { POST HRV increase } \\
\text { during stress recovery: } \\
\text { INT > C }\end{array}$ & $\begin{array}{l}\text { Decrease in } \\
\text { stress: INT \& C }\end{array}$ & $\begin{array}{l}\text { Larger physiological } \\
\text { effects in INT than } \\
\mathrm{C} \text {, no group } \\
\text { difference in } \\
\text { psychological } \\
\text { effects, inverse } \\
\text { association between } \\
\text { stress and HRV } \\
\text { modulation limited to } \\
\text { INT }\end{array}$ \\
\hline
\end{tabular}




\begin{tabular}{|c|c|c|c|c|c|c|}
\hline $\begin{array}{l}11 . \\
\text { Siepmann } \\
\text { et al. } \\
(2014)\end{array}$ & $\begin{array}{l}2 \text { weeks } \\
3 \text { sessions } \\
\text { of minimum } \\
25 \text { min / } \\
\text { week }\end{array}$ & $\begin{array}{l}\text { Paced breathing } \\
\text { guided by HRV BF }\end{array}$ & $\begin{array}{l}\text { Passive viewing } \\
\text { condition }\end{array}$ & No effects & $\begin{array}{l}\text { FU decrease in } \\
\text { chronic stress: INT }\end{array}$ & $\begin{array}{l}\text { Psychological } \\
\text { effects in INT at FU } \\
\text { but no significant } \\
\text { group differences }\end{array}$ \\
\hline $\begin{array}{l}12 . \\
\text { Sutarto et } \\
\text { al. (2012) }\end{array}$ & $\begin{array}{l}5 \text { weeks } \\
30-50 \mathrm{~min} / \\
\text { week } \\
+20 \mathrm{~min} \\
\text { daily } \\
\text { practice } \\
\text { without } \\
\text { device }\end{array}$ & $\begin{array}{l}\text { Paced breathing } \\
\text { guided by HRV BF }\end{array}$ & $\begin{array}{l}5 \text { sessions of } \\
20 \text { min } \\
\text { physiological } \\
\text { monitoring, } \\
\text { without (BF) } \\
\text { instructions }\end{array}$ & $\begin{array}{l}\text { POST increase in HRV } \\
\text { during baseline, stress and } \\
\text { recovery: INT > C } \\
\text { Decrease in breaths per } \\
\text { minute during baseline, } \\
\text { stress, and recovery: INT }\end{array}$ & $\begin{array}{l}\text { Decrease in stress: } \\
\text { INT (no direct } \\
\text { group comparison } \\
\text { performed) }\end{array}$ & $\begin{array}{l}\text { Physiological and } \\
\text { psychological effects } \\
\text { in INT but group } \\
\text { differences were not } \\
\text { always assessed or } \\
\text { significant }\end{array}$ \\
\hline $\begin{array}{l}\text { 13. Teufel } \\
\text { et al. } \\
(2013)\end{array}$ & $\begin{array}{l}8 \text { weeks } \\
21 \text { min / } \\
\text { week } \\
+ \text { daily } \\
\text { practice } \\
\text { without } \\
\text { device }\end{array}$ & $\begin{array}{l}\text { EDA BF } \\
\text { (1) specific INT: } \\
\text { food photos } \\
\text { (2) relaxation INT: } \\
\text { landscapes }\end{array}$ & WLC & $\begin{array}{l}\text { POST and FU reduction in } \\
\text { EDA: medium effect in } \\
\text { specific INT, small effect in } \\
\text { relaxation INT }\end{array}$ & $\begin{array}{l}\text { POST reduction } \\
\text { in perceived } \\
\text { stress: small } \\
\text { effect in specific } \\
\text { INT } \\
\text { FU reduction in } \\
\text { perceived stress: } \\
\text { large effect in } \\
\text { specific INT, }\end{array}$ & $\begin{array}{l}\text { Physiological and } \\
\text { psychological effects } \\
\text { in INT but no } \\
\text { significant group } \\
\text { differences }\end{array}$ \\
\hline
\end{tabular}


small effect in

relaxation INT

14.

4 to 8 weeks HRV coherence No intervention POST HRV during stress

Whited et $32 \mathrm{~min} /$

BF with exercises

al. (2014)

week

+ daily

practice for attention,

breathing and

inducing positive

emotions
No effects

INT $>$ C
Larger physiological effect in INT than C

Note. $\mathrm{BF}=$ biofeedback, $\mathrm{C}=$ control condition, $\mathrm{CBF}=$ cerebral blood flow, EDA = electrodermal activity, EMG = electromyography, FU = followup, $\mathrm{HR}=$ heart rate, $\mathrm{HRV}=$ heart rate variability, INT = intervention, $\mathrm{MR}=$ muscle relaxation, $\mathrm{TAU}=$ treatment as usual, WLC = waiting list control 
Table 4

Cross-tabulation of physiological and psychological outcomes of the biofeedback intervention as compared to the control condition.

Stress reduction No reduction in Total

stress

\begin{tabular}{lccc}
\hline Improvement in physiological & 3 & 5 & 8 \\
parameters & 1 & 5 & 6 \\
No improvement in physiological & & & \\
parameters & 4 & 10 & 14 \\
Total & & & \\
\hline
\end{tabular}


General search strategy $(\mathrm{N}=2056)$

$\rightarrow$ Removal of duplicates $(\mathrm{N}=338)$

Title and abstract screening $(\mathrm{N}=1718)$

Excluded articles based on title or abstract $(\mathrm{N}=1614)$

- Not eligible $(\mathrm{N}=1605)$

- No abstract available ( $\mathrm{N}=9)$

Full text screening $(\mathrm{N}=104)$

Excluded articles $(\mathrm{N}=90)$

- No experimental study design $(\mathrm{N}=3)$

- No randomised control trial $(\mathrm{N}=9)$

- No specifications of biofeedback intervention $(\mathrm{N}=1)$

- No physiological or psychological measurements of stress (N=68)

- Cannot be found or accessed (N=5)

- Not written in English ( $\mathrm{N}=3$ )

- No clear use of physiological feedback $(\mathrm{N}=1)$

Studies included in the review $(\mathrm{N}=14)$

Figure 1. Flow chart of the search strategy. 